Article

\title{
Conflicting Experiences With Welcoming Encounters: Narratives of Newly Arrived Refugees in the Netherlands
}

\author{
Younes Younes, Halleh Ghorashi * and Elena Ponzoni \\ Department of Sociology, Vrije Universiteit Amsterdam, The Netherlands; E-Mails: y.younes@vu.nl (Y.Y.), \\ h.ghorashi@vu.nl (H.G.), e.ponzoni@vu.nl (E.P.) \\ * Corresponding author
}

Submitted: 15 May 2021 | Accepted: 1 October 2021 | Published: 15 December 2021

\begin{abstract}
Personal networks can be both enabling and constraining in inclusion practices. This study focuses on the contribution of a particular neighborhood initiative for refugees in Amsterdam. Earlier studies have shown that in the specific context of the Netherlands' welfare state, institutional or citizen initiatives can constrain the actual inclusion of refugees. These studies argue that good intentions do not necessarily lead to inclusion because hierarchal relations reproduce subtle exclusionary structures that limit refugees' inclusion as equals. Yet, building social contacts with locals is essential for inclusion. This article shows the simultaneous presence of inclusion and exclusion by engaging with narratives from Syrian refugees participating in a six-month housing project initiated in an Amsterdam neighborhood. Residents and volunteers shared responsibilities for organizing daily life in the project. The result was an unexpected combination of Granovetter's weak and strong ties, what we call "hybrid ties," that were embedded within neighborhood dynamics and networks. Despite occasional clashes in expectations, this community-based housing project enabled specific forms of personal relationships (through hybrid ties) that were essential in refugee participants' later inclusion in the Netherlands.
\end{abstract}

\section{Keywords}

cohabiting initiatives; hybrid ties; refugee inclusion; refugee reception; societal participation; unintentional exclusion

\section{Issue}

This article is part of the issue "In Good Company? Personal Relationships, Network Embeddedness, and Social Inclusion" edited by Miranda J. Lubbers (Autonomous University of Barcelona, Spain).

(C) 2021 by the authors; licensee Cogitatio (Lisbon, Portugal). This article is licensed under a Creative Commons Attribution 4.0 International License (CC BY).

\section{Introduction}

The so-called refugee crisis that began in 2015 created a new impetus for studying possibilities and challenges regarding long-term inclusion in the countries of settlement. Several researchers referred to the years after 2015 as an exceptional period in which many societal actors engaged with (bottom-up) initiatives (Boersma et al., 2019; Feischmidt et al., 2019; Vandevoordt \& Verschraegen, 2019) and experimented with innovative approaches to refugees' integration and societal participation. In the Netherlands, bottom-up citizen engagement led to many different initiatives aiming to provide refugees access to resources, information, Dutch language learning, and opportunities to expand their social networks through both online and physical spaces for encountering locals (Rast \& Ghorashi, 2018; Smets et al., 2017).

Municipalities and local communities have invested together in novel approaches to inclusion by experimenting with different forms of housing in which refugees live with Dutch people in the same space or area. These co-housing projects have been studied as efforts to aid integration by intensifying interpersonal ties between refugees and locals through daily life activities (Kim \& Smets, 2020; Oliver et al., 2020). It will also be important to study what long-term impacts this new societal energy and political willingness has on refugees' actual inclusion in Dutch society.

Our contribution focuses on one such housing project, Hoost, and aims to answer the question of how the daily interactions and connections within the 
initiative contributed to the inclusion of refugees in the Netherlands. The first author participated in this housing project six months after arriving in Amsterdam as a refugee from Syria. The authors are all part of a research group created by author 2 , a scholar with a refugee background who has decades of experience studying the life trajectory of refugees. The author 3 is a researcher with a European migrant background.

During academic discussions on the types of interpersonal ties that offer distinct opportunities and resources, we became puzzled by disconnections between the theory and the personal experience of the first author. For example, idealized pictures of warm relations promoted by initiatives aimed at helping refugees did not match the development of relations that were merely instrumental, short lived, and colored by hierarchical imbalances. Existing research about housing projects paid little attention to personal ties among refugees themselves or to the competition for connections, information, and resources. The binary distinctions between intergroup ties providing a safe network of belonging and home and intragroup ties providing resources and connections bypassed the complexity of personal relations that in real life appeared meaningful in different ways at different times. We disentangled this complexity by engaging with participants' differentiated and multilayered experiences in the cohabiting project Hoost and reconsidered the role that personal networks have played in their processes of social inclusion.

Thus, in this article we engage with the narratives of newly arrived refugees who, along with the first author, were co-residents in Hoost. Our empirical focus is on the experiences of these refugees from the time they entered the Netherlands through their experiences as temporary residents of Hoost and afterward. Before describing our research process and findings, we first introduce the established theoretical distinctions between the types of interpersonal ties and present previous research on housing projects.

\section{Weak and Strong Ties and the Promise of Housing Projects}

Beginning in 2015, co-housing projects in the Netherlands aimed to provide favorable environments for the coexistence of refugees and local communities. However, the promise of improving refugees' inclusion through interactions with their neighbors and fellow refugees has been only partially successful. For instance, in Utrecht's Plan Einstein, asylum seekers worked and lived with young Dutch tenants. This arrangement provided access to information about study and work and helped refugees better understand the daily challenges they encountered (Oliver et al., 2020). However, the researchers also argue that conflicting objectives at the national and local level about asylum seeker reception jeopardized equal relations and constrained possibilities of friendships between refugees and Dutch tenants. Kim and Smets (2020) describe an example of a co-housing project aimed at facilitating social connections between groups (young refugees and Dutch students) who were at different stages in their lives and had different positions in terms of advantage, disadvantage, and social status. These types of intragroup ties have been studied often and are considered to enhance refugees' abilities to navigate society and access different types of resources. In this case, however, the authors argue that the project did not necessarily support refugees' integration (i.e., helping refugees acquire the relevant networks). Though the project increased the experience of home for refugees through connection with other refugees with the same background, it did not necessarily help refugees acquire the relevant networks to get ahead in the Netherlands.

Granovetter's (1973) conceptualization of "the strength of weak ties" has been used extensively to analyze the meaning of inter and intragroup relationships for social support and mobility. Granovetter showed that the strength of weak ties is due to the distribution of influence and information in relation to mobility opportunities. In his definition, a tie's strength is a combination of the amount of time spent together, the emotional intensity, the intimacy (mutual confiding), and the reciprocal services at play (Granovetter, 1973, p. 1361). Accordingly, weak ties are connections among individuals or groups who meet casually and most probably do not belong to the same homogeneous group or ethnicity. Therefore, weak ties refer to connections beyond families, relatives, or friends. In contrast, strong ties refer to the primary connections within a group, which are mostly maintained by time spent together, commonalities among the members, and shared activities in the same area of residency.

Granovetter's notion emphasized the importance of the mobility of knowledge and resources across groups. This conceptualization has been used by many migration and refugee scholars who argue that for these groups, which have limited intragroup resources in the country of residence, having weak ties is especially important because it facilitates a diverse inflow of information and influence, and enables the group to access a variety of indirect connections via different social networks. Such connections increase their chances of encountering various opportunities, thereby facilitating their social mobility and job opportunities. Wells (2011), for example, describes the effectiveness of weak ties for young refugees. These refugees' connections with volunteers in the UK Refugee Council or in language schools connect them to a range of material and cultural resources and give them access to different institutions. In their study on refugee women in Canada, Rose et al. (1998) investigated the importance of both strong and weak ties in different spaces such as churches, workplaces, language schools, and community organizations. They concluded that the women got access to relevant social networks through frontline organizations such as schools or 
churches. Weak ties developed at those sites provided gateways to resources and opportunities. But weak ties also appeared to be important in building new strong ties when they transformed into friendships. Finally, Greene (2019) described how a mixture of strong and weak ties provides the best support for migrants' integration. She showed how, at first, newly resettled refugees in the United States needed emotional support, which they found within their strong ties with friends and family members who were already there. However, these ties were too limited regarding resources and diversity to provide opportunities in the new society. The solution was the development of weak ties with cultural brokers, such as former refugees who acted as facilitators and introduced the refugees to broader resources, information, and opportunities.

Granovetter's distinction in these studies echoes the distinction between bridging and bonding social networks made popular by Robert Putnam's theory of social capital, which sees connections with friends, family, and other members of one's own social group as essential for providing material and emotional support and safety (bonding social capital), while connections with people with divergent backgrounds and interests and from different social groups are important for overcoming intragroup limitations and accessing new resources and opportunities. For example, Lancee (2010) investigated the economic integration of migrants in the Netherlands and how they use bonding and bridging social capital to achieve more benefits in the work environment. Only structural bridging social capital increased the likelihood of employment.

What has been less present in these studies on interpersonal ties and relationships and what we aim to tackle is the power dimension. In our study, it is particularly important to consider hierarchical relations involving layers of dependency and implicit expectations between refugees and locals. Hansen (2004) argues that even asking refugees if they want to be helped is a manifestation of privilege by the one who asks the question. This question puts refugees in a disadvantaged position, which sometimes leaves them in the uncomfortable situation of not being able to refuse help. The disjuncture between what people feel they need and what they think they can acceptably ask for reveals what Hansen (2004) calls the "asking rules" of reciprocity. Providing help and material support entails ingrained power issues and hidden expectations that rule gift giving (Komter, 1996), such as expectations that refugees show gratitude (Ghorashi, 2014). Earlier studies have shown that these power dynamics are quite subtle and thus normalized in the context of a welfare state such as the Netherlands (Ponzoni et al., 2017; Rast \& Ghorashi, 2018). In addition, exclusionary practices could go hand in hand with inclusionary intentions, what is referred to as the "doubleness of inclusion and exclusion" (Eijberts \& Ghorashi, 2017). In the case of recently arrived refugees, their lack of knowledge about the new context could strengthen the idea that an act of charity toward them is necessary because they are people who need help, which reinforces the hierarchical relationship between the giver and the receiver of help (Ghorashi, 2005, 2014). It is thus important to consider the hierarchical dimensions of ties emerging in encounters between refugees needing support and non-refugees engaging in civic initiatives. It is also important to focus on the relations that emerge among refugees themselves within those projects, which might create competition for connections, information, and resources and reinforce hierarchical layers in the relationships between people at different levels of disadvantage (Del Real, 2019).

\section{Methodology}

For this qualitative research, we used biographical narrative methodology for in-depth conversations (conducted March-September 2020) with a selected number of Hoost residents. Hoost residents (30 in total) consisted of three married couples, five kids, two women, and 17 men. This distribution was reflected in the selected research participants: nine men and one woman, with diversity in age (24-48 years old), marital status, education level, and home area in Syria. Initially, participants chose the location for their interviews, but ultimately, most interviews were done through video calls due to COVID-19 limitations. Interviews were conducted in Arabic, and the recordings were later translated and transcribed into English by the first author. In addition, we included an autobiography from the first author, who was also a Hoost resident. His position as ex-resident was essential in creating the necessary trust for the in-depth conversations with other residents. The combination of these narratives served as a window into the often inaccessible, intense emotional experiences of newly arrived refugees. The narratives evoke images and sensations that can help readers gain a deeper understanding of certain situations (see also Davis \& Nencel, 2011). In addition, emphasizing the autobiographical nature of the first author's narrative by using "I" creates grounds for readers to emotionally identify with the narrator and enables readers to situate themselves within certain memories, both of which are crucial for understanding locations, interactions, and processes in a more profound manner (Haynes, 2006; Keyworth, 2001; Walker, 2017). Furthermore, the first author's personal experience functioned as a continual source of reflection and discussion. To analyze the narratives, we adapted "dialogical listening" (Van Laer \& Janssens, 2014) by moving back and forth between the narratives and the multiple sources of knowledge that came from our specific positionings. Our different positionings as authors (a former refugee, a Western migrant, and a newly arrived refugee) created various levels of personal, societal, and academic knowledge that added an extra angle to "dialogical listening." The narratives revealed what was important to the narrators about their lives, the people and places 
they identified with, and the meanings they attached to them (Kohler-Riessman, 2008). Many scholars have shown the importance of such methods for marginalized groups, such as women (Anderson \& Jack, 1991; Ardener, 1975) and refugees (Ghorashi, 2008). Due to the first author's dual position as researcher and ex-resident, close-reading of the narratives and distinguishing the dominant patterns with the co-authors was essential. The balance between distance and attachment was a regular point of reflection.

To provide a broader context to the narratives, we next present an autobiographical reflection on the first author's initial encounters with refugee reception in the Netherlands.

\section{Arriving in the Netherlands}

When I first arrived at Amsterdam's central train station in September 2015, I congratulated myself that I had arrived and my mission was accomplished. I was finally here and not in a war zone. Now I would have a new, good life. I had heard many stories about different countries along the way, but for me, the choice of the Netherlands was clear. I did not know many people there, but I could speak English, which made the Netherlands favorable (many people told me that knowing English might not be helpful in some countries, such as Germany). The first place I was taken was a sports hall in East Amsterdam, where I met most of the people interviewed for this research.

Our first week there, we were overwhelmed by the warm welcome from the neighborhood and the number of volunteers who came daily. It created a nice connection between us and the Dutch volunteers. However, this warm welcome ended when we were moved to Havenstraat in Amsterdam South (for more see Rast et al., 2020). Havenstraat was an abandoned old prison with high fences and narrow corridors. This transfer was like having a bucket of cold water dumped on your head: a feeling shared by all of us from the sports hall. There was a great contrast between the warmth of our initial welcome and the coldness of that prison. Luckily, some of us had kept in touch with some of the Dutch volunteers from the sports hall, and I made some Syrian friends as well. These connections added warmth and a sense of security and support within the old prison. Though I did not have high expectations for them at the time, these connections later became quite valuable.

We were soon transferred again to another emergency shelter located in Heumensoord, a forest outside Nijmegen (eastern Netherlands). We were confused about what was happening because there was absolutely no communication from any institution. It was hard to leave the limited network we had built in Amsterdam and go to a city on the other side of the country. When we arrived at Heumensoord, I remembered back to my arrival in Amsterdam, when I had thought my mission was accomplished. How wrong I was.

\section{Heumensoord}

Heumensoord was one of the most discussed emergency shelters in the Netherlands because of its exceptionally bad (some said inhuman) conditions (Van der Wal, 2016). The shelter, which was managed by COA (Agency for the Reception of Asylum Seekers; a governmental organization tasked with arranging shelter for asylum seekers in the Netherlands), was designed to house 3,000 refugees. Big tents were divided into eight pavilions. Each pavilion had 12 rooms, each with eight beds. Nobody knew how long they would be staying there. Asylum seekers had to adapt to the new situation, the isolated location, and the bad conditions:

I expected the Netherlands would be easier than it was or better than it was. Once, when they put us in that very huge camp in Nijmegen-so many people. There was no hygiene, no healthy situation, a very large number of people. Everything was bad. (RA, 36 years old Syrian man, married, low education)

Another respondent, AA, is a pharmacist and father from Syria. I met him in the Amsterdam sports hall, where we helped other refugees with translations because we were two of the few people who spoke English:

When we arrived in Nijmegen, at first I thought it was a joke. It's a joke or prank somebody is playing on you. And you think like, oh, things will get better. On that day, the COA lady came and she was like a police officer. She said you have to behave and you have to, yeah, to act in a certain way....I realized that this is the place I'm in, and I will stay here for a long time, and it's a bad situation. I have to find a way to live with it. But then I started to feel, I will not call it depression, because I compared it with the war in Syria, I realized it was much better than living in war. (AA, 36-year-old Syrian man, married, high education)

Heumensoord residents ended up spending nearly six months in an emergency shelter situation without any knowledge of when they could start their asylum procedures (see also Smets et al., 2017). This ambivalent situation contributed to their increasing vulnerability. To survive the living conditions in Heumensoord, asylum seekers looked to the volunteers who came to the camp to help them. More than 2000 volunteers registered to get connected and help refugees in various ways, for instance, by inviting them for coffee or to play sports outside the camp and helping them learn the language (Smets et al., 2017). A form of convergence took place between helpers, the volunteers, and those who needed help, the refugees. MS, a 27-year-old Syrian man who came to the Netherlands with his wife, said the relationships back then were not the type of connection he was hoping for: 
The big step was when we moved to Nijmegen, when we stayed in the AZC [asylum seeker center] there. We realized that we were going to stay for months, so we had to do something. Then we started to go out and started meeting people just to get a sense of social life and get a sense of, yeah, being a human being. But that wasn't really satisfying, or we weren't ready. Yeah, doesn't really fit with your need to be like a human being and socially connect with other people. Because it was limited or just constrained by the fact that you were a refugee who just arrived in the Netherlands, who needs help, and who was vulnerable for everything. And when Dutch start from this assumption of the relationship, that's not really like the best base on which you can create, like, the relationship that I wanted at that time.

Refugees expected to have equal relationships with volunteers, but such connections were usually not possible, because any potential connection was conditioned by the refugees' situation as inhabitants of an emergency shelter. However, some refugees were able to create such relationships. OD, for example, used his long-term experience as an artist to present himself:

Presenting myself as educated and in particular as an artist, that was via the online platform Yalla Foundation Nijmegen, helped me to connect with a Dutch painter. This painter introduced me to other painters also. I was able to practice my talent, or my hobby at least. Meanwhile, the other refugees were just waiting and doing nothing. I have to mention or recognize that, because I have a certain degree in education, that helps me. It gives me a different position in different places. Being an artist is a nice idea for them, for the Dutch; they like it and that opens doors for you. (OD, 43-year-old Syrian-Palestinian man, married, high education)

For OD, being helped by other artists like himself did not feel negative because he was being helped as a newly arrived professional and not so much as a refugee. However, it was not possible for everyone to make that kind of connection, either because they did not want to or because they could not find anyone to connect with. RA, for example, mostly stayed in his room with some of his friends, and he clearly felt excluded because he only spoke Arabic: "In Nijmegen, the Dutch were only communicating with those who were speaking in English or Dutch." According to RA, mastery of at least one of those two languages was required for relationships with the volunteers in Nijmegen, a requirement that created distance and deficits for those who spoke neither language.

\section{Hoost: Experimenting with Connectedness}

The Hoost initiative began in 2015 in Amsterdam's Indische neighborhood as an alternative to the much- criticized formal reception policy used in asylum seeker centers run by COA (Larruina et al., 2019; Larruina \& Ghorashi, 2016; Rast et al., 2020). The local government and a housing agency made an empty building available as a temporary residence (February-August 2016) for some refugees from Heumensoord. Discussions about this initiative began in November 2015. The plan was to provide a house for 30 refugees for six months under the COA's responsibility. The 30 residents were selected by three Syrians (including the first author) and the initiator on the basis of the selectors' previous knowledge of them. The selectors considered age (18-23) and family situation to find an appropriate mix of people for the project. For those selected, this opportunity provided much needed certainty in an uncertain period of waiting for decisions on asylum applications and for permanent places to live. By the time residents moved to Hoost in March 2016, all but two had been granted residence permits.

AA was part of the decision group of four and was also very active in gathering the needed furniture and arranging the interior space:

The advantage of Hoost was that we set up everything from zero. The first time we saw it was at night. At that first sight, we were dismayed. But then you see the potential that it can be something livable. At the same time, you see very empty and big-huge-empty spaces. It was difficult to recognize rooms, so we had to work very hard. (AA, 36-yearold Syrian man, married, high education)

The Hoost organizers were a team of four Dutch volunteers who were not residents themselves but who spent a lot of time in the house. Each had a different responsibility: daily life of the 30 residents; finances inside the house; thinking about the next steps for the residents; arranging new places for the residents to live (ideally permanent houses) after the initiative ended. All residents had to sign an agreement to meet certain obligationsfrom following Dutch classes to cleaning the house and arranging their finances with the organizers' help.

Hoost as an experiment had different and even contradicting meanings for the residents, which will be discussed in the next section. But the most important reason behind this experiment was formulated nicely by MS:

Hoost was kind of a social experiment to try to discover the best way to integrate the newcomers in Amsterdam or in the Netherlands overall. So, the idea was that people have to move as soon as possible from the AZC and get into the city to get into their real lives, just making relationships, building networks, on an equal basis. Many volunteers came to Hoost trying to help by bringing stuff. So basically, the furniture at Hoost was provided by people who were really trying to help. (MS, 27-year-old Syrian man, married, high education) 
In that transformational period, all Hoost residents were enthusiastic and optimistic about being recognized as human beings and living in a place where they were not reduced to numbers, as is often the case in formal institutions.

\section{Safety Net(work)}

Despite their enthusiasm regarding the encounter with the volunteers, refugees were struggling with personal issues: What do I need? What about my family in Syria? Should I go back to school or start a business? Intensive interactions with the communities involved in this project led to the volunteers creating a safety net or support system for the residents. AA provided an example:

My family was in Syria, and Aleppo was at war. Back then, I was thinking there is no room for exceptions. I asked a volunteer if I could accelerate the procedure for family reunification. This woman, this volunteer, said: "No, but we can try. We can try as we did with Hoost." She talked to other people who helped with the application. (AA, 36-year-old Syrian man, married, high education)

However, the project's setup itself revealed some complications. One was the equivocality in the structure of daily life at Hoost. For some, it was not easy to live with other residents who shared the space and to not have complete ownership about the rules, regulations, and roles, all of which were the domain of the organizers:

There were no clear lines, no clear roles-what we had to do, what we didn't have to do-let people organize themselves. There was disagreement, everyone would choose the best for them, everyone would choose to do the very least thing. And there would be rivalry and disagreements....For me, there was $100 \%$ no development, because I wasn't really focused on the follow-up or investing in myself, I was just waiting to get to my own home to start the life that I wanted. (MS, 27-year-old Syrian man, married, high education)

Another complication was the experience of inequality in relationships with volunteers. MS provides insight in this regard:

There were no equal relationships, they all were formalized in a way. Okay, these are refugees, these people need help, and we're going to help them because they are poor people or because they are kind of unqualified people. They are less-skilled people. So we have to help them.

Despite organizers' and volunteers' efforts to be attentive to the needs of refugees and their space, there were occasions that refugees felt that their needs and their privacy were ignored:

I remember the people or the guys who were teaching the language, they were knocking on our doors and rooms: "Open up! Wake up! I came here to give you a lesson." And I'm already woken up or something like that, I cannot speak....Privacy is just priceless. I enjoyed my privacy a lot when I got my own house and lived by myself. That was exactly when I knew what I wanted, what I wanted to do. (CA, 24-year-old man, single, studied high school in Syria)

During the project, the organizers devoted time to residing in the building so they could be of help. Yet, the assumption that residents needed help seemed to mean that they would be willing to accept that help without consideration of their availability. This created a somewhat contradictory experience in comprehending the nature of the connection: Was it is just a volunteer helping a refugee or did it have the potential to become an equal friendship? Thus, Hoost provided a safety net(work) for residents in a very insecure period in their lives, but the intensity of the support was also disruptive, especially when that support was embedded within certain assumptions that took away residents' privacy and agency.

\section{Neither Weak nor Strong}

Soon after the residents moved in, the living boundaries became elastic. Space was shared intensively during the day with the Dutch organizers and volunteers, which led to various connections. Hoost manifested as a magnet of weak ties in the city, according to Granovetter's definition. Support for Hoost was strong, and it received relatively high media coverage in the Netherlands. It provided space for volunteers from all over the country who were willing to spend varying levels of intensity and time to engage with the residents. RA provides an example:

There was one language volunteer whose name is $\mathrm{K}$, and he did me a big favor. Really. He helped me a lot with the language. He saw me helping other Hoost inhabitants for free with renovating and painting. He is a very good person and he is very sensitive. He also wants to help everybody, but especially with me, he helped me a lot. He wanted to support and assist me. He saw me helping people for free, so he found a paid job in painting with a contract for me. (RA, 36 years old Syrian man, married, low education)

This connection between RA and the volunteer grew through the elastic living boundaries at Hoost and the combined time and intimacy. SH offers another example:

While we were having a Dutch language lesson, one of these teachers introduced me to her friend, who introduced me to the architect academy. I went 
with her and made a tour there and met with the study advisor. I had an idea about the situation, and I started to plan for study for a master in the academy. I received a phone call from somebody who owns a company, and he said he knew there was an architect in Hoost and he would like to offer me an internship with them. (SH, 32-year-old Syrian man, married, high education)

The time spent learning the language gave $\mathrm{SH}$ an opportunity to talk about himself and his competencies, thereby converting being a language student to being a job applicant.

These findings indicate that spending large amounts of time with Hoost volunteers created possibilities for residents to connect to other networks (weak ties) and to develop a kind of closeness and intimacy (strong ties) with the volunteers, which helped them access new resources. However, some residents were unable to make such connections; others felt unseen and neglected in the provision of new resources. And, naturally, for the residents who received less attention or had fewer interactions, the presence of volunteers had a rather negative impact, coming close to what Del Real (2019) refers to as toxic ties. EM even went so far as to call it nepotism:

Because there was a lot of nepotism from volunteers and organizers. Mainly those who spoke English got a lot of benefits, and some guys in Hoost, we were not treated fairly. And the Dutch tended to communicate with people who spoke English. Some of those who were speaking English were making us feel like we didn't deserve to be in Hoost because we didn't speak English. (EM, 34-year-old Syrian woman, married, middle education)

Sharing time and space in such an intimate manner (a family of strangers) did not facilitate good relationships among the refugees themselves either. MS considers that period a difficult one:

I wasn't really happy with Hoost and I was hoping to get out as soon as possible. I can't say directly why, but it just didn't feel very good to live there. Yeah. I think it's mainly because I was there with my wife. We had our own room, but still, we had to share the bathroom with 30 to 35 people there. We had to share the kitchen, we had to share the washing machine and everything we had to share, except our bed. There was limited privacy and... in our own room, we could hear everything that was going on outside. I bet everyone could hear me talking to my wife.

In sum, the Hoost project was shown to be quite challenging both internally and externally. The assumption that a shared ethnic and refugee background would enable a temporary homemaking experience proved to be unreal- istic. Externally, despite the amount of positive energy from the community, the mismatch of expectations showed the complexity involved in refugee-volunteer relationships. The unique aspect of this project (its temporal intensity) and our access to deeper layers of the residents' experiences (because of the first author's position) enabled us to discover an additional aspect in the type of ties that were created-what we call "hybrid ties." The ties that developed between refugee residents and engaged non-residents (initiators, volunteers, journalists, students, and engaged neighbors) can be seen as hybrid in part because they show temporary moments of intense connection without the continuity of a long-term meaningful relationship. They also contain aspects of strong ties (such as friendship and intimacy) with the benefits of weak ties (enabling access to new resources).

\section{Discussion and Conclusion}

In this article, we engaged with narratives from Syrian refugees who were residents of Hoost, an alternative temporary home. We challenged the models in which ties and networks are approached as either weak (and presumably bridging) or strong (to create bonding), arguing that ties do not fit simple dichotomies. Indeed, our results found hybrid ties that contained elements of both weak and strong ties. Those hybrid ties showed that the complex, nuanced, layered, and diverse aspects of intragroup and intergroup relationships were important ingredients in the life trajectories of the refugees participating in our study. Many residents thought Hoost provided a safety net(work) during a very insecure period in their lives, especially compared to the cold reception system in asylum centers, where relations with formal institutions or with "distant" volunteers were sometimes dehumanizing. They felt supported in practical aspects of living in a new context and learned how to navigate different aspects of the Dutch system.

This study also reveals and disentangles a vital layer not included in models that theorize on ties and their effects and value, namely: hierarchical power relations. Our findings showed that although the residents felt seen and approached as human beings and not reduced solely to the category of refugees, inclusion and exclusion were simultaneously present, as this experiment was also ingrained with certain normalized assumptions about refugees that hampered creating equal relationships with locals. The idea of refugees as needing help led to hierarchical forms of relationships between givers (locals) and receivers (refugees) of help. The unbalanced reciprocity led to paradoxical situations in which volunteers were sometimes pushing boundaries in offering their help, which some residents felt as an intrusion on their privacy. Expecting someone to be available at all times-and to be thankful-expresses an unequal reciprocity in a relationship as compared to the subtle expectations involved in gift exchanges (Hansen, 2004; Komter, 1996). 
Also, although some residents were asked to work with the initiators to co-design the living conditions at Hoost, many felt that they did not have ownership of the choices made in what was supposed to be their house. Because this experiment attracted many locals from the city and many national media outlets, residents sometimes wondered who had actual ownership of Hoost and whether it could be considered a real home. They had to deal with myriad strangers who could come and go as they pleased. This forced intimacy undermined residents' sense of autonomy. However, getting to know volunteers on a personal level also led to advantages, as in the case of $A A$, who, through a trusted relation with a volunteer, was able to receive help in his family reunification process.

This living situation led to the simultaneous presence of strong and weak ties at various levels. Initiators, for example, had an office in the building and were partially cohabitating with the residents in a very intensive manner. In addition, they co-designed the living conditions and programs for different activities, such as the Dutch language course, together with selected residents. They were also the gatekeepers of the project, they talked to the media and other officials about the project, and they organized financial support (for example, through crowdfunding). Many others, such as volunteers who came to help or students who were doing research on the project, were also spending long periods of time in the house. Indeed, locals and residents were partly "living" together (sharing responsibilities for organizing daily life within the project) yet living apart (because locals had their own homes outside the project). This created a condition of living together intensively for a limited period of time in a given day or of having intimate conversations about each other's lives, yet not being connected through relationships based on equality, instead keeping distinct positions as locals and refugee residents. This simultaneous presence of intensity with temporality, or temporal intensity, connecting often distanced lifeworlds (of newly arrived refugees and of local residents) and existence of normalized power relations created hybrid ties. Thus, several factors contributed to the emergence of hybridity in the ties: (a) the specific context of a large increase in societal initiatives to welcome refugees; (b) the temporal intensity of this particular project (living together yet apart, for a limited period of time); and (c) the normalized (thus unquestioned) hierarchical relationship between volunteers and refugees. The hybrid ties showed a combination of elements of strong ties (coinhabiting and co-shaping an experimental space like Hoost and sharing intimate conversations and friendship) with the instrumental nature of weak ties (providing access to information and resources).

While research on personal connections in situations of disadvantage has focused on the idea of protection through intragroup connections and community resilience (Frounfelker et al., 2020; Hanley et al., 2018), our study questions this assumption by show- ing the layeredness of such situations. Participants' narratives show the existence of hierarchical dimensions, be it refugees' disadvantages in relation to locals or their differences in privilege among themselves, that lead to competition for resources, connections, and information. Del Real (2019) describes such inequalitybased relationships among undocumented migrants in the United States immigration system as "toxic ties." Whereas Del Real discussed a context in which relations among migrants were disrupted by resources being completely institutionally controlled, our research suggests the importance of refugees' own resources (such as knowing the language or having specific types of education or work experience), which attracted differing levels of attention from volunteers. The experience of being ignored (as a few refugees narrated) when there is so much positive energy around could have a toxic edge even when there is no intention to exclude those involved. In the case of Hoost, the intensity of close contact, emotional dependency, and sharing tasks went hand in hand with weak connections (due to the lack of a sense of community, the temporary nature of the stay, and the lack of intimacy), in some cases exacerbating already existing distances.

In sum, Hoost had strong enabling aspects by providing a safety net(work) for newly arrived refugees who were in very uncertain situations. It also provided opportunities to make connections with a large number of locals, which helped participating refugees find their way in their new society and navigate the unknown Dutch system. These aspects not only had short-term effects but also enabled long-term possibilities regarding jobs, education, and friendships. However, despite its good intentions, the initiative also had constraining aspects that were present from the start. We hope this analysis creates reflective possibilities that help citizen initiatives enlarge their capacity to enable refugees' inclusion.

\section{Acknowledgments}

We would like to thank the Dutch Research Council (NWO) for making this research financially possible.

\section{Conflict of Interests}

The authors declare no conflict of interests.

\section{References}

Anderson, K., \& Jack, D. C. (1991). Learning to listen: Interview techniques and analyses. In S. B. Gluck \& D. Patai (Eds.), Women's words: The feminist practice of oral history (pp. 11-27). Routledge.

Ardener, E. (1975). Belief and the problems of women. In S. Ardener (Ed.), Perceiving women (pp. 1-19). J. M. Dent.

Boersma, K., Kraiukhina, A., Larruina, R., Lehota, Z., \& Nury, E. O. (2019). A port in a storm: Spontaneous vol- 
unteering and grassroots movements in Amsterdam. A resilient approach to the (European) refugee crisis. Social Policy \& Administration, 53(5), 728-742.

Davis, K., \& Nencel, L. (2011). Border skirmishes and the question of belonging: An authoethnographic account of everyday exclusion in multicultural society. Ethnicities, 11(4), 467-488.

Del Real, D. (2019). Toxic ties: The reproduction of legal violence within mixed-status intimate partners, relatives, and friends. International Migration Review, 53(2), 548-570.

Eijberts, M., \& Ghorashi, H. (2017). Biographies and the doubleness of inclusion and exclusion. Social Identities: Journal for the Study of Race, Nation and Culture, 23(2), 163-178.

Feischmidt, M., Pries, L., \& Cantat, C. (Eds.). (2019). Refugee protection and civil society in Europe. Palgrave Macmillan.

Frounfelker, R. L., Tahir, S., Abdirahman, A., \& Betancourt, T. S. (2020). Stronger together: Community resilience and Somali Bantu refugees. Cultural Diversity and Ethnic Minority Psychology, 26(1), 22-31.

Ghorashi, H. (2005). Agents of change or passive victims: The impact of welfare states (the case of the Netherlands) on refugees. Journal of Refugee Studies, 18(2), 181-198.

Ghorashi, H. (2008). Giving silence a chance: The importance of life stories for research on refugees. Journal of Refugee Studies, 21(1), 117-133.

Ghorashi, H. (2014). Racism and 'the ungrateful other' in the Netherlands. In P. Essed \& I. Hoving (Eds.), Dutch Racism (pp. 101-116). Rodopi.

Granovetter, M. (1973). The strength of weak ties. The American Journal of Sociology, 78(6), 1360-1380.

Greene, R. N. (2019). Kinship, friendship, and service provider social ties and how they influence wellbeing among newly resettled refugees. Socius: Sociological Research for a Dynamic World, 5, 1-11.

Hanley, J., Al Mhamied, A., Cleveland, J., Hajjar, O., Hassan, G., Ives, N., Khyar, R., \& Hynie, M. (2018). The social networks, social support and social capital of Syrian refugees privately sponsored to settle in Montreal: Indications for employment and housing during their early experiences of integration. Canadian Ethnic Studies, 50(2), 123-148.

Hansen, K. V. (2004). The asking rules of reciprocity in networks of care for children. Qualitative Sociology, 27(4), 421-437.

Haynes, K. (2006). Linking narrative and identity construction: Using autobiography in accounting research. Critical Perspectives on Accounting, 17(4), 399-418.

Keyworth, S. A. (2001). Critical autobiography: 'Straightening' out dance education. Research in Dance Education, 2(2), 117-137.

Kim, K., \& Smets, P. (2020). Home experiences and homemaking practices of single Syrian refugees in an innovative housing project in Amsterdam. Current Sociol- ogy, 68(5), 607-627.

Kohler-Riessman, C. (2008). Narrative methods for human sciences. SAGE.

Komter, A. E. (1996). Reciprocity as a principle of exclusion: Gift giving in the Netherlands. Sociology, 30(2), 299-316.

Lancee, B. (2010). The economic returns of immigrants' bonding and bridging social capital: The case of the Netherlands. International Migration Review, 44(1), 202-226.

Larruina, R., Boersma, K., \& Ponzoni, E. (2019). Responding to the Dutch asylum crisis: Implications for collaborative work between civil society and governmental organizations. Social Inclusion, 7(2), 53-63.

Larruina, R., \& Ghorashi, H. (2016). The normality and materiality of the dominant discourse: Voluntary work inside a Dutch asylum seeker center. Journal of Immigrant \& Refugee Studies, 14(2), 220-237.

Oliver, C., Geuijen, K., \& Dekker, R. (2020). Social contact and encounter in asylum seeker reception: The Utrecht Refugee Launchpad. Comparative Migration Studies, 8(1), 1-19.

Ponzoni, E., Ghorashi, H., \& van der Raad, S. (2017). Caught between norm and difference: Narratives on refugees' inclusion in organizations. Equality, Diversity and Inclusion: An International Journal, 3(3), 222-237.

Rast, M. C., \& Ghorashi, H. (2018). Dancing with 'the other': Challenges and opportunities of deepening democracy through participatory spaces for refugees. Social Inclusion, 6(1), 188-198.

Rast, M. C., Younes, Y., Smets, P., \& Ghorashi, H. (2020). The resilience potential of different refugee reception approaches taken during the 'refugee crisis' in Amsterdam. Current Sociology, 68(7), 853-871.

Rose, D., Carrasco, P., \& Charboneau, J. (1998). The role of "weak ties" in the settlement experiences of immigrant women with young children: The case of Central Americans in Montréal (Working Paper No. 4). CERIS.

Smets, P., Younes, Y., Dohmen, M., Boersma, K., \& Brouwer, L. (2017). Sociale media in en rondom de vluchtelingennoodopvang bij Nijmegen [Social media in and around the refugee emergency shelter in Nijmegen]. Mens en Maatschappij, 92(4), 395-420.

Van der Wal, C. (2016, February 11). Hoe kamp Heumensoord uitliep op een miskleun [How camp Heumensoord turned out to be a failure]. $A D$. https:// www.ad.nl/buitenland/hoe-kamp-heumensoorduitliep-op-een-miskleun a9eb1bb4

Van Laer, K., \& Janssens, M. (2014). Between the devil and the deep blue sea: Exploring the hybrid identity narratives of ethnic minority professionals. Scandinavian Journal of Management, 30(2), 186-196.

Vandevoordt, R., \& Verschraegen, G. (2019). Citizenship as a gift: How Syrian refugees in Belgium make sense of their social rights. Citizenship Studies, 23(1), 43-60. 
Walker, A. (2017). Critical autobiography as research. The Qualitative Report, 22(7), 1896-1908.

Wells, K. (2011). The strength of weak ties: The social networks of young separated asylum seekers and refugees in London. Children's Geographies, 9(3/4), 319-329.

\section{About the Authors}

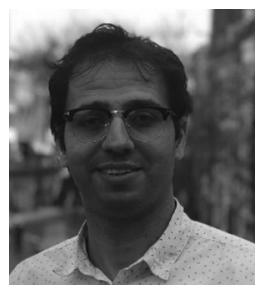

Younes Younes is a researcher in the Department of Sociology at VU Amsterdam, the Netherlands, and a member of the Refugee Academy (Institute of Societal Resilience, VU). He is also co-founder of Yalla Foundation, an active organization in refugees' inclusion in the Netherlands. His most recent publication, "Social Media in and Around a Temporary Large-Scale Refugee Shelter in the Netherlands" (co-authored with P. Smets, M. Dohmen, K. Boersma, and L. Brouwer), is in the journal Social Media + Society.

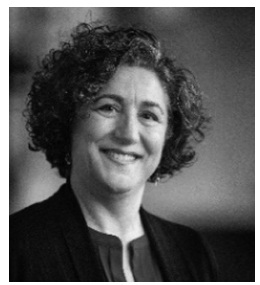

Halleh Ghorashi is full professor of diversity and integration in the Department of Sociology at VU Amsterdam and a member of KNAW (the Royal Netherlands Academy of Arts and Sciences). Her most recent edited volume publications are: Contested Belonging: Spaces, Practices, Biographies (2018, together with K. Davis and P. Smets; Emerald) and Scholarly Engagement and Decolonisation: Views from South Africa, The Netherlands and the United States (2020, together with M. Crul, L. Dick, and A. Valenzuela; Sun Media).

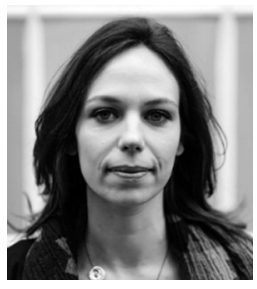

Elena Ponzoni is an assistant professor in the Department of Sociology at the VU Amsterdam and is affiliated with the research group Youth and Society at the Inholland University of Applied Sciences. Her current research focuses on the inclusivity of youth services, inclusive conditions for community engagement, refugee advocacy, and the ability of engaged scholarship projects to cogenerate inclusive societal structures. She is also coordinator of the Refugee Academy, an academic platform that aims to connect societal and academic actors involved in refugee inclusion. 